\title{
Progress on an old question for stock assessment of the edible crab Cancer pagurus
}

\author{
Matt R. J. Sheehy ${ }^{1, *}$, Andrew E. Prior ${ }^{1,2}$ \\ ${ }^{1}$ Department of Biology, University of Leicester, University Road, Leicester LE1 7RH, UK \\ ${ }^{2}$ Present address: Smith \& Nephew Research Centre, York Science Park, Heslington, York YO1 5DF, UK
}

\begin{abstract}
Stock assessments for the edible crab Cancer pagurus have been limited by an inability to determine its age. We applied neurolipofuscin-based ageing techniques to this problem for the first time. We constructed a neurolipofuscin concentration frequency distribution for a sample of crabs from the western English Channel and found clearly resolved modes, which we interpreted as annual cohorts. These enable the calibration of neurolipofuscin concentration to chronological age under natural conditions and in the absence of known-age microtags. The resulting crab age determinations offer an unprecedented demographic perspective of the most important English regional crab fishery and substantially reduce uncertainty in previous growth estimates. A cubic von Bertalanffy model is the best fit to the new size-at-age data, reflecting progressive growth in early juveniles. On average, recruitment to legal size in both sexes is at $4+\mathrm{yr}$, but individual growth is highly variable so that size recruitment is protracted across $\sim 5$ year-classes. C. pagurus lives to $\sim 9 \mathrm{yr}$ in the western English Channel; natural mortality rates of $\sim 0.48$ are higher than previous estimates. Age compositions indicate past year-class strength fluctuation, with a particularly strong settlement in 1995-a relatively warm year. Reinterpretation of size compositions in light of the neurolipofuscin results suggests that it may be possible to detect some cohorts in stratified adult size frequency data. These findings will strengthen the basis for sound management and sustainability of this important bioresource and will provide guidance for wider application of the neurolipofuscin ageing method.
\end{abstract}

KEY WORDS: Age determination - Cancer pagurus - English Channel · Growth · Longevity · Mortality $\cdot$ Neurolipofuscin $\cdot$ Stock assessment

\section{INTRODUCTION}

Probably known as 'carabus' by the Romans, the edible crab Cancer pagurus has been harvested for centuries (Edwards 1979). Today it is one of the most commercially important decapods in western Europe, with recent annual landings of ca. 46 million $\mathrm{kg}$, worth ca. GB £50 million (FAO 2006). Governments are responsible for ensuring the sustainable exploitation of this bioresource under both national and EU law, and the best available science is required to underpin assessment and management. Stock demographic information is a prerequisite for assessment, but the question of edible crabs' age has proved problematic for at least a century. Pearson (1908, p. 186) noted that 'it is quite impossible to state the age of a crab with any degree of certainty'. As for most other crustaceans, growth by moulting of the exoskeleton means that no annuli comparable to those in finfish bones are available for age reading. Growth rate is highly variable, such that individual size is not a good proxy for age (Edwards 1979). Based on an analysis of data from a large sample of intertidal juveniles, Bennett (1974, p. 818) concluded that it was '...extremely difficult (if not impossible) to distinguish the modes of a size frequency distribution of $C$. pagurus which might indicate year classes or moult classes ... there appears to be too much overlap of moult classes, even at an early stage, to permit their separation...' . The crab is difficult to rear for a prolonged period in the laboratory and its 
migratory habits severely limit tag returns. Edwards (1989, p. 256) emphasized that it was 'dangerous to make fishery management recommendations without some knowledge of the exploited stock' and pointed out some biological parameters of 'extreme importance to management', including mortality and growth rates, recruitment and longevity. Following their reassessment of English east coast stocks, Addison \& Bennett (1992) reiterated the need for further studies to refine parameter estimates. Subsequently, Bennett (1995, p. 95) stated that 'the inability to age large crustaceans has made the estimation of mortality parameters difficult and has stifled the use of age-based assessment methods developed originally for finfish ... The modelling approach taken with $C$. pagurus has therefore been relatively simplistic'.

More recently, progress has been made on differentiation of moult and age groups of sub-tidal juvenile crabs. Up to 5 instars within the young-of-the-year $(0+)$ age group were detected in size frequency distributions of crabs up to $8.8 \mathrm{~mm}$ carapace width (CW) collected by diver suction sampling, and the $0+$ size cohort appears to be discrete from older cohorts (Robinson \& Tully 2000, D. Eaton pers. comm.). Beam trawl surveys suggest that occasionally it may be possible to trace very strong year classes for 2 or $3 \mathrm{yr}$ in successive size frequency distributions (D. Eaton pers. comm.). However, there still appear to be no published examples of moult or age groups in size frequency distributions for legal-sized crabs.

In the present study, we used novel lipofuscin ageing technology to address the very long-standing problem of Cancer pagurus age determination. Lipofuscin is an autofluorescent, biochemically heterogeneous, but phylogenetically highly conserved, subcellular residue derived from secondary lysosomes. It accumulates predictably over time in the post-mitotic tissues of most eukaryotic organisms. Ultrastructurally, lipofuscin contains partially degraded organelle fragments, notably mitochondria, and recent molecular analyses indicate the presence of post-translationally modified proteins derived from radical-mediated reactions including lipid peroxidation- or glucoxidation-induced damage, in particular, by malondialdehyde, 4-hydroxynonenal, and advanced glycation end products (Fonseca et al. 2005). These observations suggest that lipofuscin accumulation represents a net outcome of the interplay between an inevitable feature of normal cellular catabolism; the dependence on, or production of, potentially harmful compounds such as free radicals on the electron transport chain; and various imperfect systems that have evolved to protect against, eliminate or repair the damage caused by such compounds, such as autophagocytosis, proteolysis and exocytosis. The widely observed inverse relationship between lipofus- cin accumulation rate and lifespan suggests that lipofuscin cytotoxicity itself, or the damage underlying its formation, may be centrally involved in the ageing process (Fonseca et al. 2005).

Since Ettershank's (1983) landmark proposal that lipofuscin might prove useful as a tool for age determination in ecology, this concept has undergone continuous research, development and validation, and there has been considerable recent progress in its application to crustacean fishery assessment contexts. With reliable quantification procedures, the analysis of in situ lipofuscin in neural tissue (neurolipofuscin) can provide age determinations with year-class resolution, even for the most difficult long-lived species such as clawed lobsters (Sheehy \& Bannister 2002). However, application of this technique to edible crab (and many other species) poses a particular challenge in that no known-age microtag recaptures are available for calibrating the relationship between neurolipofuscin concentration and chronological age under natural environmental conditions. We overcome this problem using intrinsic time reference points, i.e. cohort modes in neurolipofuscin concentration frequency distributions (NCFDs) for samples of the wild population. These modes are not instars; elsewhere they have been confirmed as chronological groupings by comparison with known-age individuals (Sheehy et al. 1998, Fonseca \& Sheehy 2007) and by analysis of seasonal changes in neurolipofuscin accumulation rate in a time series of NCFDs (Kodama et al. 2006). Although neurolipofuscin itself accumulates as a function of physiological ageing, because NCFD modes arise from periodic spawning events, they provide markers of the passage of calendar time. Neurolipofuscin accumulation patterns appear to be highly conserved across species (Sheehy \& Bannister 2002, Fonseca et al. 2005) and we use these similarities to help interpret the present results. We report the first age determinations for Cancer pagurus from one of the most productive regional fisheries, that in the western English Channel, along with resulting population assessment parameters. We discuss some of the implications of these new results. We also use them to help reinterpret adult size frequency distributions.

\section{MATERIALS AND METHODS}

Crab samples. A total of 228 juvenile Cancer pagurus, from 8 to $113 \mathrm{~mm} \mathrm{CW}$, were obtained by thoroughly searching under fucoid-covered boulders in the lower intertidal zone during spring ebb tides at Thurlestone Rock, Devon, UK (50 $\left.15.4^{\prime} \mathrm{N}, 03^{\circ} 51.4^{\prime} \mathrm{W}\right)$, on 6 collection trips between February 12 and April 10, 2001. A total of 298 live, legal-sized C. pagurus, from 
137 to $259 \mathrm{~mm} \mathrm{CW}$, fished in the western English Channel in the vicinity of Start Point, Devon, were purchased from a wholesale fish merchant at Beesands, Devon $\left(50^{\circ} 15.1^{\prime} \mathrm{N}, 3^{\circ} 39.2^{\prime} \mathrm{W}\right.$, ca. $15 \mathrm{~km}$ east of the intertidal collection site) in 5 shipments between June 15 and August 16, 2002. This sample was stratified by $0.5 \mathrm{lb}$ (227 g) mass class to achieve as even a coverage as practicably possible of the full male and female size ranges of landings for the fishery. Live crabs were held for up to $1 \mathrm{wk}$ in marine tanks at the University of Leicester, UK, prior to sampling for neurolipofuscin.

Neurolipofuscin quantification. Following findings for Homarus gammarus that bilateral variability in measured neurolipofuscin concentration in Cell Cluster A of the eyestalk terminal medulla (MT-A) was lower than that in the olfactory lobe cell mass of the brain (Sheehy \& Shelton 2001), we conducted all neurolipofuscin measurements on the eyestalk neural tissue of Cancer pagurus. We successfully measured neurolipofuscin concentration in 197 intertidal and 293 fished crabs using histological and confocal imaging methods similar to those reported previously for other decapods (Sheehy 2002a). Briefly, a rectangular image $(132 \times 88 \mu \mathrm{m})$ within every serial wax section (avg. $n=17$ ) of the MT-A containing the hemiellipsoid bundle (the main fibre tract connecting the MT-A to the hemiellipsoid body) was acquired at a high objective magnification (63× oil with a 1.6 zoom producing an effective objective magnification of $100 \times$ ). The size of the image frame was smaller than the total extent of the MT-A in each section. Its position was chosen to include the highest concentration of neurolipofuscin associated with the globuli neurosomata (relatively small and uniformly sized mature neurones) comprising the cell mass, while at the same time minimizing the inclusion of large neurosomata, indeterminate particles, particularly on section margins, axon tracts, holes, blood spaces, and potential proliferative areas devoid of neurolipofuscin. The extent of globuli neurosomata contained within each image was manually outlined using COMOS v. 7 software (Bio-Rad). Brightly autofluorescing neurolipofuscin granules within this outline were then discriminated by grey-scale thresholding. The area fraction of neurolipofuscin in each image was calculated as the ratio of the total cross-sectional area of neurolipofuscin granules over the total cross-sectional area of globuli neuro- somata contained within each image. Neurolipofuscin concentrations for individual crabs were calculated as weighted geometric averages of the percentage area fractions of neurolipofuscin in each of the replicate MT-A images (Sheehy et al. 1998). As a quality control, we tested the bilateral reproducibility of neurolipofuscin measurements in left and right eyestalks over the full range of concentrations encountered to date in C. pagurus (0 to $9.5 \%$ vol, Fig. 1) and found this to be high $(\mathrm{r}=0.96, \mathrm{n}=69, \mathrm{p}<0.0001)$.

Calibration of neurolipofuscin concentration to chronological age. From the measurements above, we constructed a NCFD for the sample of legal-sized crabs. Because signal discrimination in frequency distributions is sensitive to histogram configuration, we systematically analyzed a wide range of bin widths and bin starts and assessed by eye the effect on modal discrimination as detailed in Sheehy \& Prior (2005).
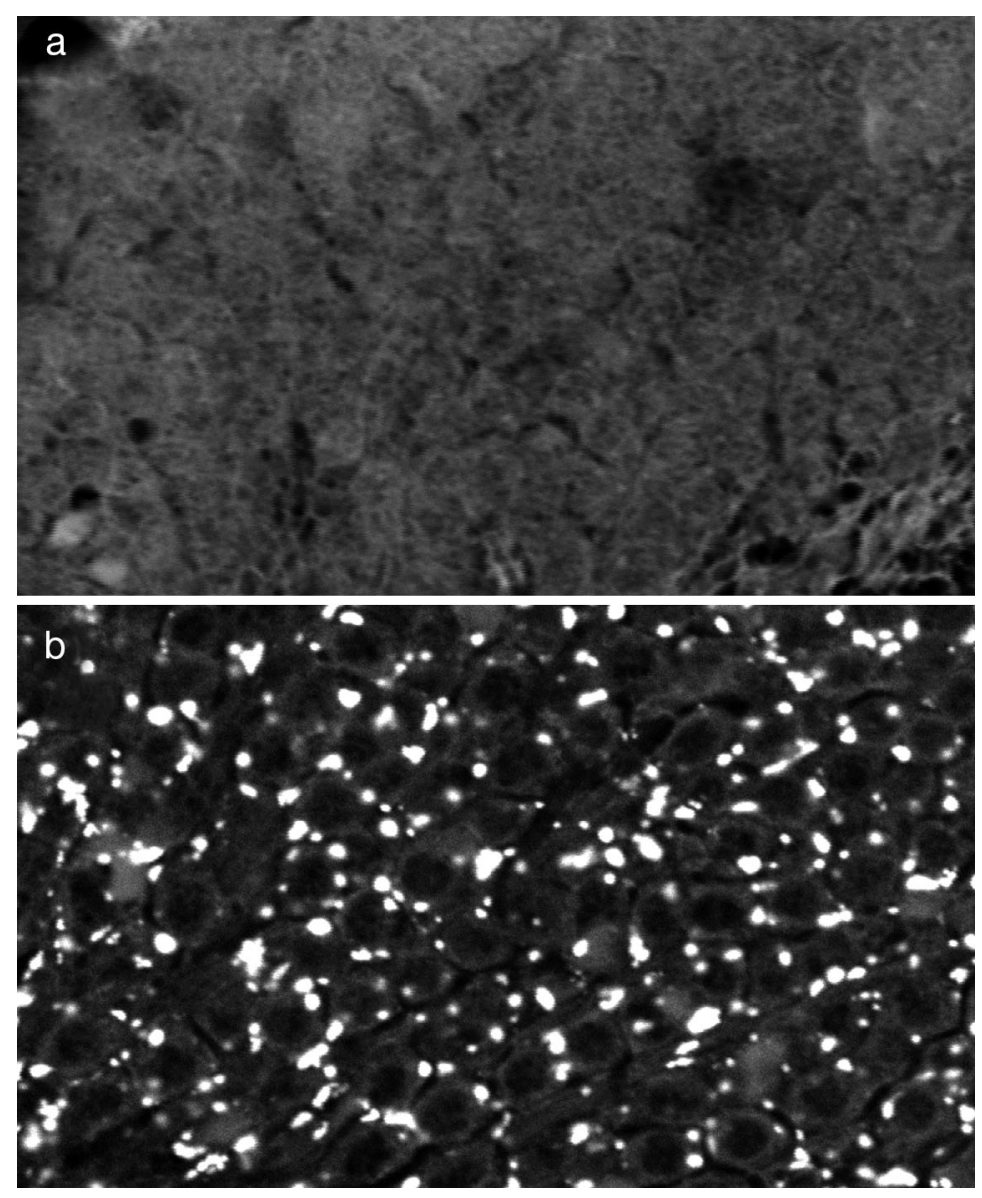

Fig. 1. Cancer pagurus. Age-associated accumulation of autofluorescent neurolipofuscin granules in Cell Cluster A of the eyestalk terminal medulla in (a) a female crab of $16.2 \mathrm{~mm}$ carapace width (CW), ca. 6 mo old, showing no resolvable neurolipofuscin; and (b) a physiologically very old female crab of $202 \mathrm{~mm} \mathrm{CW}$, averaging $9.5 \%$ by volume of neurolipofuscin; both images show $132 \times 88 \mu \mathrm{m}$ areas from $6 \mu \mathrm{m}$ thick unstained wax sections excited by confocal laser at $514 \mathrm{~nm}$ 
Initial bin widths were selected on the basis of a priori expectations of annual neurolipofuscin accumulation rate based on Cancer pagurus habitat temperature and published lifespan estimates, both of which can be related to annual neurolipofuscin accumulation rate (Sheehy 2002b, Fonseca et al. 2005). Modal resolution was found to be relatively insensitive to bin width over a certain midrange. Within this range, for comparative purposes, we selected a bin width $(0.22 \%$ vol $)$ such that the bulk of the observations were contained within the same number of bins as in our size frequency distribution for the same sample, the latter being constructed with a standard $5 \mathrm{~mm}$ class interval (substantially smaller than the expected annual growth increment). We constructed a similarly configured NCFD for the sample of intertidal crabs. In order to minimize analysis effort while maximizing histogram sample size (France et al. 1991), we pooled the male and female neurolipofuscin data (Sheehy et al. 1998) on the basis that no significant sex differences have been found in neurolipofuscin accumulation patterns in any previous studies on known-age arthropods (Fonseca et al. 2005). We analyzed the modal compositions of NCFDs using semi-automated peak-fitting routines in PeakFit v. 4 software (SPSS) without prior smoothing or baseline subtraction. For the fishery NCFD, Gaussian components were fitted directly to local maxima. For the intertidal NCFD, which lacked clear maxima, a Savitzky-Golay algorithm was used to produce a smooth second derivative of the frequency data, from which peaks were then identified by local minima. Peak resolution was assessed with the separation index (SI) (Sparre \& Venema 1998):

$$
\mathrm{SI}=\frac{\bar{Y}_{i+1}-\bar{Y}_{i}}{\left(S_{i+1}+S_{i}\right) / 2}
$$

where $\bar{Y}_{i}$ is the mean CW or neurolipofuscin concentration of the ith mode and $s_{i}$ is its standard deviation. Below an SI of 2, differentiation of adjacent modes is considered to be virtually impossible. We generally interpreted NCFD modes as annual cohorts on the basis of C. pagurus' univoltine reproduction. However, in the NCFD for intertidal crabs, the initial bin interval (no resolvable neurolipofuscin) contained crabs ranging up to $88 \mathrm{~mm} \mathrm{CW}$. Since modal analysis of the size frequency distribution for the intertidal sample suggested that individuals in this size range were mainly from $0+$ and $1+$ cohorts, we concluded that the onset of neurolipofuscin accumulation was in the second year after settlement. We assigned the 'hidden' $0+$ cohort in this NCFD a separation index of 0 . We use the conventional cohort age designations $0+, 1+, 2+$, etc. to refer to individuals 0 to 1,1 to 2,2 to $3 \mathrm{yr}$ old and so forth. We assumed a 'birth' date for all individuals of September 1, which corresponded approximately to the peak of larval settlement (Robinson \& Tully 2000). We added 0.5 and $0.8 \mathrm{yr}$ to the relative ages of all cohorts in the intertidal and fishery NCFDs, respectively, on the basis that the median collection dates for these samples were 6 and 10 mo, respectively, after the 'birth' date. We then fitted a linear regression to the concatenated age-related progression of modes from the intertidal and fisheries NCFDs after weighting each modal neurolipofuscin concentration by the normalized reciprocal of the modal variance to obtain unbiased regression parameters. TableCurve 2D v. 5 software (SPSS) was used for regression fitting. We took the regression intercept and slope to be indicators of onset and average annual rate of neurolipofuscin accumulation, respectively, in C. pagurus at the study location. We inverted this calibration equation to estimate the ages of individual crabs from their eyestalk neurolipofuscin concentrations.

Precision of age estimates. In the absence of knownage microtag data for Cancer pagurus, there was no direct way of determining $95 \%$ confidence limits for age predictions. However, it was possible to infer precision based on neurolipofuscin data from several previous studies on known-age decapods in various environments (Sheehy \& Bannister 2002) and more recent additional data for signal crayfish Pacifastacus leniusculus (Fonseca et al. 2003) and African migratory locust Locusta migratoria (Fonseca et al. 2005). These data encompass 639 individuals in 78 known age groups from 8 arthropod species and show a highly conserved relationship between the mean neurolipofuscin concentration, $\overline{\mathrm{NC}}$, of a cohort and its standard deviation, $s_{\overline{N C}}$, which is defined by the power function:

$$
S_{\overline{\mathrm{NC}}}=a \overline{\mathrm{NC}}^{b}
$$

where $a=0.2439$ and $b=0.7190(\mathrm{r}=0.9, \mathrm{p}<0.0001)$. In other words, if a cohort's mean neurolipofuscin concentration is taken as a proxy for its physiological age, variability in individual neurolipofuscin concentrations, NC, can be said to increase with advancing physiological age (and by calibration, chronological age) in a highly predictable way (Fig. 2e in Sheehy \& Bannister 2002). Use of this conserved relationship to infer the precision of C. pagurus age estimates involved 4 steps.

First, we obtained transformed variables, $Y$ and $X$, that optimally homogenized the variance in the abovementioned relationship, as follows:

$$
\begin{aligned}
Y & =(\mathrm{NC}+\mathrm{c})^{1-b} \\
X & =(\overline{\mathrm{NC}}+\mathrm{c})^{1-b}
\end{aligned}
$$

where $\mathrm{c}$ is a small constant (0.01) used to eliminate zero values. 
Second, we employed inverse regression procedures (Sokal \& Rohlf 1981, p. 498) to estimate the lower, $\mathrm{LL}_{\widehat{X}^{\prime}}$ and upper, $\mathrm{UL}_{\bar{X}^{\prime}}, 95 \%$ confidence limits, respectively, for predictions of $\bar{X}_{i}$ from $Y_{i}$ as:

$\mathrm{LL}_{\widehat{X}_{i}}=\overline{\bar{X}}+\frac{b_{Y \cdot X}\left(Y_{i}-\overline{\bar{Y}}\right)}{b_{Y \cdot X}^{2}-t_{0.05[\mathrm{n}-2]}^{2} s_{b}^{2}}$

$-\frac{t_{0.05[\mathrm{n}-2]}}{b_{Y \cdot X}^{2}-t_{0.05[\mathrm{n}-2]}^{2} s_{b}^{2}} \sqrt{s_{Y \cdot X}^{2}\left[b_{Y \cdot X}^{2}-t_{0.05[\mathrm{n}-2]}^{2} s_{b}^{2}\left(1+\frac{1}{\mathrm{n}}\right)+\frac{\left(Y_{i}-\overline{\bar{Y}}\right)^{2}}{\sum x^{2}}\right]}$

$\mathrm{UL}_{\bar{X}_{i}}=\overline{\bar{X}}+\frac{b_{Y \cdot X}\left(Y_{i}-\overline{\bar{Y}}\right)}{b_{Y \cdot X}^{2}-t_{0.05[\mathrm{n}-2]}^{2} S_{b}^{2}}$

$+\frac{t_{0.05[\mathrm{n}-2]}}{b_{Y \cdot X}^{2}-t_{0.05[\mathrm{n}-2]}^{2} s_{b}^{2}} \sqrt{s_{Y \cdot X}^{2}\left[b_{Y \cdot X}^{2}-t_{0.05[\mathrm{n}-2]}^{2} s_{b}^{2}\left(1+\frac{1}{\mathrm{n}}\right)+\frac{\left(Y_{i}-\overline{\bar{Y}}\right)^{2}}{\sum x^{2}}\right]}$

where $\overline{\bar{X}}=0.845, \overline{\bar{Y}}=0.838, b_{Y \cdot X}=1, \mathrm{n}=639, s_{b}=$ $0.0094, s_{Y \cdot X}^{2}=0.0046$ and $\Sigma X^{2}=508.093$.

Third, we untransformed $\mathrm{LL}_{\bar{X}_{i}}$ and $\mathrm{UL}_{\bar{X}_{i}}$ as follows:

$$
\begin{aligned}
& \mathrm{LL}_{\overline{\mathrm{NC}}}=\mathrm{LL}_{\overline{\mathrm{X}}_{i}}^{(1-b)-1}-\mathrm{C} \\
& \mathrm{UL}_{\overline{\mathrm{NC}}}=\mathrm{UL}_{\bar{X}_{i}}^{(1-b)^{-1}-\mathrm{C}}
\end{aligned}
$$

Fourth, we converted $\mathrm{LL}_{\overline{\mathrm{NC}}}$ and $\mathrm{UL}_{\overline{\mathrm{NC}}}$ into estimates of the lower and upper $95 \%$ confidence limits, respectively, for individual Cancer pagurus age estimates by inserting these values into the calibration equation obtained from modal progression analysis.

Assessment parameter estimation. To obtain growth parameters, we assessed the goodness of fit of a large number of conventional and non-standard models to our size-at-age observations using TableCurve 2D v. 5 software (Systat). Of the best fitting models selected by eye, the one with the highest $\mathrm{r}^{2}$ was chosen. This was the cubic form of the von Bertalanffy equation, which we found to be well suited to the early lag in growth apparent in the data:

$$
L_{T}=I_{\infty}\left(1-\mathrm{e}^{-k\left(T-t_{0}\right)}\right)^{3}
$$

where $L_{T}$ is $\mathrm{CW}(\mathrm{mm})$ at age $T(\mathrm{yr}), l_{\infty}$ is the mean $\mathrm{CW}$ of the oldest individuals, and $k$ is the rate at which $l_{\infty}$ is reached. To achieve a realistic model fit through the youngest age group, which lacked neurolipofuscin but which was resolvable by size, regression fits were forced through weighted dummy observations representing the size of megalopae at settlement $(2 \mathrm{~mm} \mathrm{CW}$, age $0 \mathrm{yr})$ and the mean size of individuals in the youngest apparent cohort in the intertidal size frequency distribution $(14.2 \mathrm{~mm}$ $\mathrm{CW}$, age $\sim 0.5 \mathrm{yr}$ ). We used a robust regression fitting procedure employing Pearson minimization to produce the most likely fit. Once parameter estimates were obtained, we refitted an appropriately constrained regression to the original data without dummy observations in order to obtain an unbiased coefficient of determination and confidence intervals. Mean age at recruitment to the fishery $t_{\mathrm{c}}$ and its $95 \%$ prediction limits were obtained directly from the intercepts of the growth curve and its $95 \%$ prediction limits with minimum landing size, 140 and $160 \mathrm{~mm} \mathrm{CW}$ for females and males, respectively. We estimated mean maximum longevity $\left(t_{\max }\right)$ as the average of the oldest $5 \%$ of individual neurolipofuscin age estimates in the sample. Total mortality rate $Z$ was obtained by applying conventional linearized catch curve analysis to our age-structured data. For this we used 6 monthly, rather than annual, age classes in order to maximize the number of data points for regression fitting. We weighted the agewidth key from our 2002 fishery sample by the average size composition of western English Channel (Start Point inshore) landings for the period 2000 to 2002 (courtesy of CEFAS, Lowestoft). We used a $3 \mathrm{yr}$ average of landings, rather than data for 2002 alone, because available size compositions were subject to sampling limitations, such that an average was considered to give a more realistic indication of the existing population size structure. We estimated natural mortality rate $M$ by applying $t_{\max }$ to Hoenig's (1983) empirically derived relationship, which was based on data from 134 minimally exploited populations of 79 fish, mollusc and cetacean species $\left(r^{2}=\right.$ $0.82)$ :

$$
\ln (M)=1.44-0.982 \ln \left(t_{\max }\right)
$$

Fishing mortality rate $F$ was estimated as $Z-M$.

Reinterpretation of adult size frequency data. In view of technical difficulties reported in the literature (Bennett 1974), we re-evaluated our size frequency data for the presence of potential cohorts in light of new growth information obtained from neurolipofuscin analysis. We fitted Gaussian components to the size frequency distributions using the same method applied to the fishery NCFD. Any cohorts that were detected by NCFD but not by size were assigned a separation index of 0 in the size frequency analysis. We then compared the modal progression from this analysis with the expected generalized growth trajectory from the neurolipofuscin age-length data in order to assess the possibility that the size modes represented annual cohorts. 

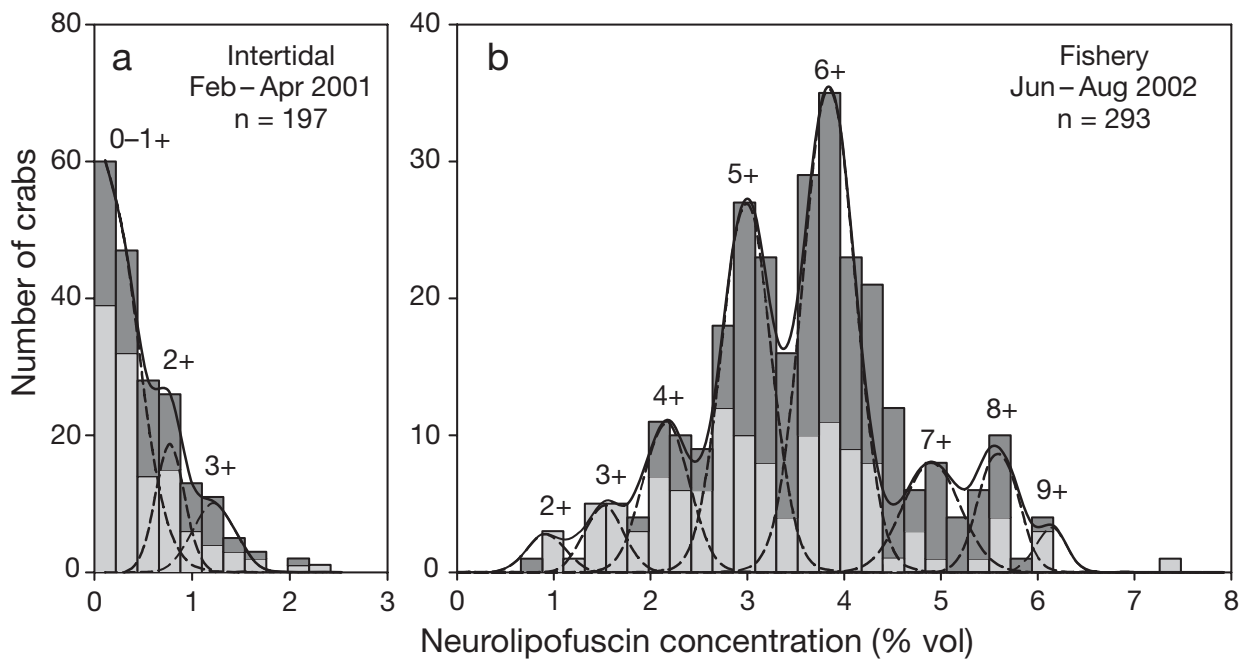

Fig. 2. Cancer pagurus. Modal analysis of neurolipofuscin concentration frequency distributions for (a) intertidal and (b) fishery samples of $\mathrm{crab}_{\text {; light }}$ grey and dark grey bars: female and male, respectively; dashed and solid lines: bestfitting Gaussian components and cumulative Gaussian fit, respectively; 0+ to 9+: annual cohort designations

\section{RESULTS}

\section{Neurolipofuscin measurement and age estimation}

All fitted peaks exhibited separation indices greater than the critical value of 2. However, cohorts were not clearly resolved by eye in the intertidal NCFD (Fig. 2a) due to the steeply descending limb of the distribution in combination with the negligible concentrations of neurolipofuscin in the youngest crabs. Modal analysis nevertheless detected 3 peaks in this NCFD, the first apparently being composed primarily of 2 age classes, $0+$ and $1+$, distinguishable only by size, as previously noted. By contrast, the fishery NCFD exhibited 8 well-separated modes (Table 1, Fig. 2b), the progression of which indicated a gen- erally linear neurolipofuscin accumulation pattern (Fig. 3) defined by the following relationship:

$$
\mathrm{NC}=0.756 T-1.245
$$

where NC is neurolipofuscin concentration (\% vol) and $T$ is post-settlement age (yr) $\left(\mathrm{r}^{2}=0.99, \mathrm{p}<0.00001\right)$. Minor deviations from linearity were interpreted as being due to the effect of inter-annual variation in mean sea temperature. We could not exclude the possibility that an additional mode existed between the putative $6+$ and $7+$ peaks in Fig. $2 \mathrm{~b}$, but in our judgement the slightly greater spacing between these peaks relative to others and the slightly asymmetrical shape of the $6+$ mode were more likely to be due to effects on neurolipofuscin accumulation rate from sea temperature fluctuations around 1995. In any event, exclusion

Table 1. Cancer pagurus. Modal analysis of the intertidal (Feb-Apr 2001) and fishery (Jun-Aug 2002) size and neurolipofuscin concentration frequency distributions (Figs. $2 \& 7$, respectively). $\bar{Y}$ : average; ?: mode not resolved; SI: separation index; CW: carapace width; na: not applicable

\begin{tabular}{|c|c|c|c|c|c|c|c|c|}
\hline \multirow{2}{*}{ Mode } & \multirow{2}{*}{$\begin{array}{l}\text { Mean age } \\
(y r)\end{array}$} & \multirow{2}{*}{$\begin{array}{l}\text { Year- } \\
\text { class }\end{array}$} & \multicolumn{3}{|c|}{ Neurolipofuscin concentration (\% vol) } & \multirow[b]{2}{*}{$\bar{Y} \pm \mathrm{SD}$} & \multirow{2}{*}{$\begin{array}{l}\mathrm{CW}(\mathrm{mm}) \\
\% \text { of sample }\end{array}$} & \multirow[b]{2}{*}{ SI } \\
\hline & & & $\bar{Y} \pm \mathrm{SD}$ & $\%$ of sample & SI & & & \\
\hline \multicolumn{9}{|c|}{ Intertidal } \\
\hline $0+$ & 0.5 & 2000 & ? & ? & na & $14.6 \pm 4.7$ & 12 & na \\
\hline $1+$ & 1.5 & 1999 & $0 \pm 0.31$ & 79 & 0 & $44.7 \pm 5.6$ & 48 & 5.8 \\
\hline $2+$ & 2.5 & 1998 & $0.78 \pm 0.15$ & 12 & 3.4 & $?$ & $?$ & 0 \\
\hline $3+$ & 3.5 & 1997 & $1.22 \pm 0.22$ & 9 & 2.4 & $?$ & ? & 0 \\
\hline \multicolumn{9}{|c|}{ Fishery } \\
\hline $2+$ & 2.8 & 1999 & $0.95 \pm 0.14$ & 2 & na & $?$ & $?$ & na \\
\hline $3+$ & 3.8 & 1998 & $1.48 \pm 0.17$ & 4 & 3.4 & $142 \pm 3.4$ & 9 & 0 \\
\hline $4+$ & 4.8 & 1997 & $2.15 \pm 0.23$ & 10 & 3.4 & $157 \pm 5.0$ & 11 & 3.6 \\
\hline $5+$ & 5.8 & 1996 & $3.00 \pm 0.25$ & 27 & 3.5 & $173 \pm 6.6$ & 28 & 2.8 \\
\hline $6+$ & 6.8 & 1995 & $3.81 \pm 0.22$ & 38 & 3.4 & $193 \pm 6.2$ & 26 & 3.1 \\
\hline $7+$ & 7.8 & 1994 & $4.90 \pm 0.30$ & 9 & 4.2 & $214 \pm 9.0$ & 26 & 2.8 \\
\hline $8+$ & 8.8 & 1993 & $5.60 \pm 0.20$ & 7 & 2.8 & $?$ & $?$ & 0 \\
\hline $9+$ & 9.8 & 1992 & $6.14 \pm 0.15$ & 2 & 3.1 & $?$ & $?$ & 0 \\
\hline
\end{tabular}




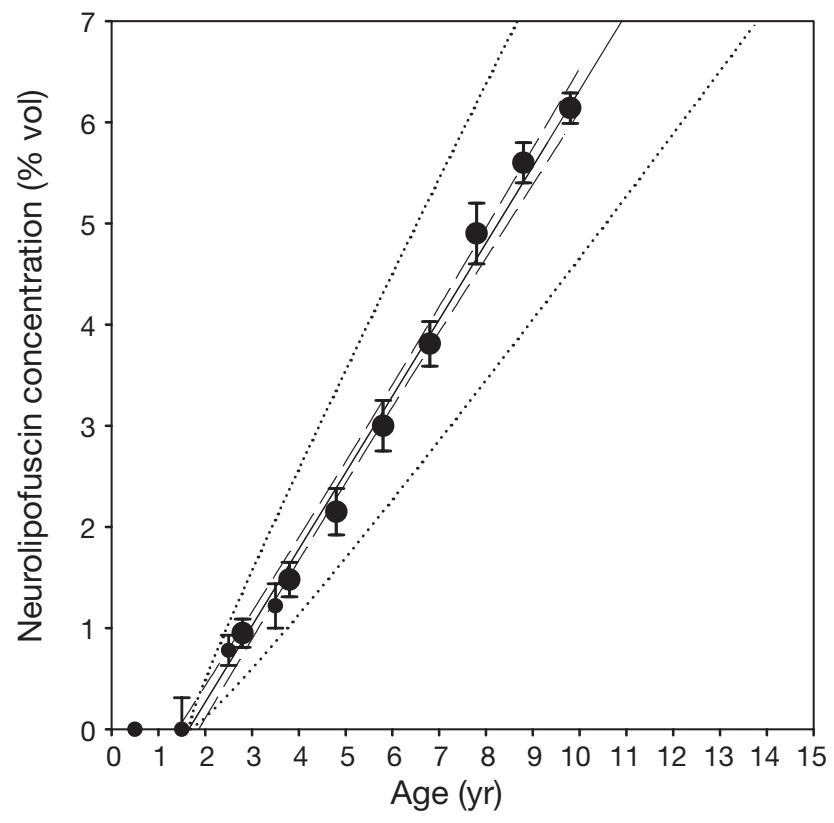

Fig. 3. Cancer pagurus. Modal progression analysis of neurolipofuscin concentration frequency distributions; small and large circles: mean (modal) \pm SD cohort neurolipofuscin concentrations for the intertidal and fishery samples of crab, respectively; solid and dashed lines: best-fitting linear model and its $95 \%$ confidence limits, respectively; dotted lines: inferred $95 \%$ confidence limits for individual age estimates based on a comparative analysis of variance patterns in known-age cohorts from other arthropod species (see 'Materials and methods' for details)

of the $7+, 8+$ and $9+$ peaks from the modal progression analysis had negligible influence on the regression coefficients, as did exclusion of the 2+ and 9+ peaks, both of which had low sample sizes. By inference from other species, the $95 \%$ prediction interval for individual neurolipofuscin-based age estimates for Cancer pagurus would widen with increasing age (Fig. 3). For example, age estimates of 2, 7 and 12 yr would incur $95 \%$ prediction intervals of 1.8 to $2.4,5.6$ to 9.1 and 9.6 to $15.2 \mathrm{yr}$, respectively.

\section{Population parameters}

Population parameters based on neurolipofuscin age estimates for Cancer pagurus in the western English Channel are given in Table 2. At this location there is little difference in the average growth rates of male and female $C$. pagurus prior to recruitment to the fishery (Table 2, Fig. 4). The average times $\left(t_{\mathrm{c}}\right)$ taken to reach minimum landing sizes (MLS) of 140 and $160 \mathrm{~mm} \mathrm{CW}$ are 4.1 and $4.8 \mathrm{yr}$ for females and males, respectively. Thereafter, males achieve an $l_{\infty}$ that is approximately $35 \mathrm{~mm}$ greater
Table 2. Cancer pagurus. Neurolipofuscin-estimated population parameters for the western English Channel. MLS: minimum landing size (carapace width, $\mathrm{mm}$ ) at the time of sampling; $l_{\infty} k$ and $t_{0}$ : cubic von Bertalanffy growth model parameters; $t_{\mathrm{c}}$ : mean age at recruitment to legal size (yr) with $95 \%$ prediction interval in parentheses; $t_{\max }$ : mean and range (in parentheses) of the oldest $5 \%$ of individuals in the sample; $Z, M, F$ : total, natural and fishing mortality rates, respectively

\begin{tabular}{|lcc|}
\hline & Female & Male \\
\hline MLS & 140 & 160 \\
$l_{\infty}$ & 203.4 & 238.5 \\
$k$ & 0.46 & 0.38 \\
$t_{0}$ & -0.54 & -0.60 \\
$t_{\mathrm{c}}$ & $4.1(2.6-7.7)$ & $4.8(3.2-7.9)$ \\
$t_{\max }$ & $9.1(7.5-11.5)$ & $9.0(8.6-9.7)$ \\
$Z$ & 0.93 & 1.16 \\
$M$ & 0.48 & 0.49 \\
$F$ & 0.45 & 0.67 \\
\hline
\end{tabular}

than that for females of the same age. Despite moderately strong overall relationships between size and age (female, $\mathrm{r}^{2}=0.84, \mathrm{n}=233, \mathrm{p}<0.0001$; male, $\mathrm{r}^{2}=$ $0.85, \mathrm{n}=247, \mathrm{p}<0.0001$ ), individual growth variation is already relatively large in juveniles in the lower intertidal nursery ground, which range up to $\sim 5 \mathrm{yr}$ of age, and by the time crabs reach legal size, $\sim 5$ yearclasses, 3 to 8 yr of age, enter the fishery each year. Subsequently, as growth of adults slows substantially, the relationship between size and age in commercial landings is poor, especially for males (females, $\mathrm{r}^{2}=$ 0.37, $\mathrm{n}=118, \mathrm{p}<0.0001$; males, $\mathrm{r}^{2}=0.09, \mathrm{p}=0.0001$ ) although remaining statistically significant. Horizontal and vertical clusters in the size-at-age data (Fig. 4) are suggestive of instars and annual cohorts, respectively.

Based on the present sample, both male and female Cancer pagurus in the western English Channel reach a $t_{\max }$ of around $9 \mathrm{yr}$, with maximum individual age estimates not much more than this. The descending limbs of both female and male linearized catch curves were able to be fitted with requisite significant linear regressions explaining relatively high proportions of the variance $\left(r^{2}=0.72, n=8, p=0.008\right.$ and $r^{2}=0.85$, $\mathrm{n}=7, \mathrm{p}=0.003$, respectively), but there were indications of year-class strength fluctuation (Fig. 5). Note that the exclusion of the oldest female data point had minimal effect on the regression slope (-0.95 instead of -0.93). No clear sex differences in mortality rates where detected, and $M$ and $F$ were estimated to contribute to $Z$ in roughly equal proportions. The dominant component in 2002 landings of both males and females was the 1995 year class, but there were probably contributions from as long ago as 1992 to as recently as 2000 (Fig. 6). 


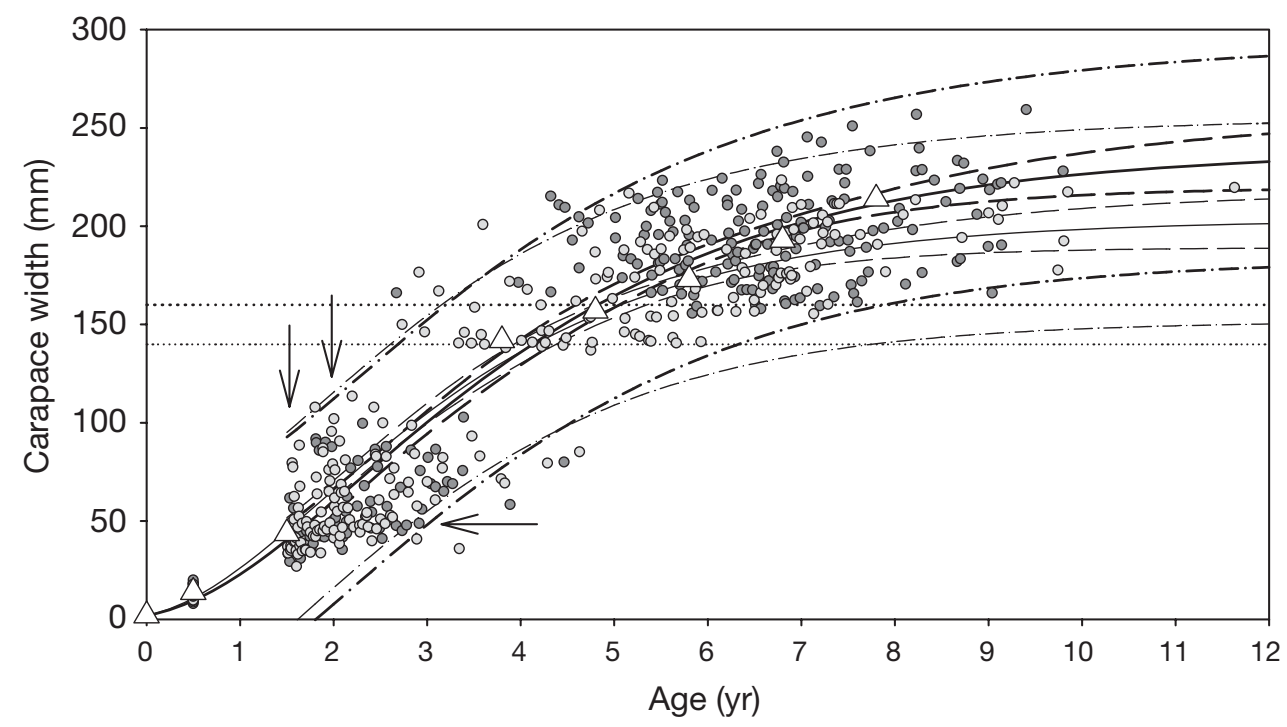

Fig. 4. Cancer pagurus. Neurolipofuscin-estimated size-at-age relationship for crabs in the western English Channel, except for crabs $<20 \mathrm{~mm}$ CW, whose age was estimated from size-frequency analysis; the gap in data coverage for sub-legal crabs between ca. 120 and 140 to $160 \mathrm{~mm} \mathrm{CW}$ is due to paucity of larger crabs in the intertidal zone; light grey and dark grey symbols: female and male, respectively; solid, dashed and dotted-dashed lines (males in bold): best-fitting cubic von Bertalanffy model and its $95 \%$ confidence and prediction limits, respectively; dotted horizontal lines: minimum landing sizes for females (140 mm CW) and males (160 mm CW; in bold) at the time of sampling; horizontal and vertical arrows: evidence of size- and age-clustering of observations suggestive of instars and year classes, respectively; open triangles: annual average sizes starting from newly settled megalopae and then as suggested by modal analysis of intertidal and fishery size frequency distributions (see Fig. 7)

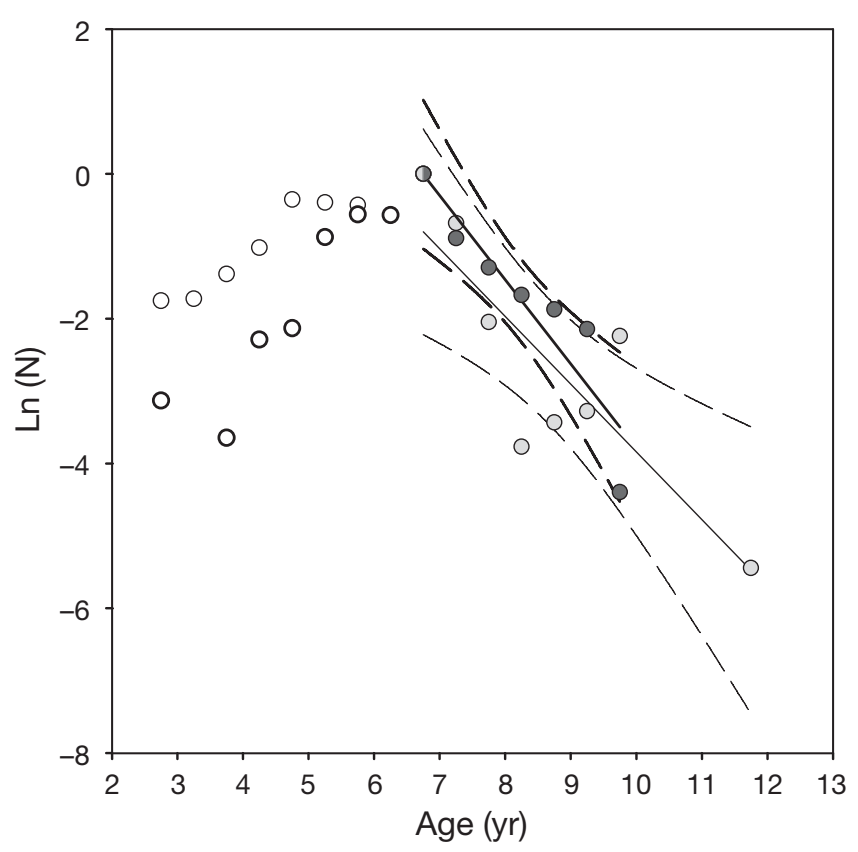

Fig. 5. Cancer pagurus. Neurolipofuscin-estimated catch curves for western English Channel inshore landings for 2002; light grey and dark grey symbols: female and male, respectively; solid and dashed lines (males in bold): best-fitting linear model and its $95 \%$ confidence limits, respectively, after excluding partially recruited age classes (open symbols, males in bold); to assist comparison, numbers (N) are normalized to 1 for the strongest age class in each sex

\section{Size frequency distributions}

In contrast to the NCFD, the size frequency data for intertidal crabs (Fig. 7a) showed 2 wellseparated peaks at 15 and $45 \mathrm{~mm} \mathrm{CW}$, which we interpreted to represent the $0+$ and $1+$ cohorts, respectively (Fig. 7a, Table 1). Although 3 smaller additional peaks were present at larger sizes in this distribution, it was not possible to differentiate these from noise with confidence. The fishery size frequency distribution showed 5 more or less visually obvious modes that were mostly less well separated than those in the fishery NCFD (Fig. 7b, Table 1). In particular, the resolution of older cohorts was poorer than in the NCFD. Transposition of the progression of these modes onto the neurolipofuscin-derived generalized growth curve (Fig. 4) strongly suggested that the modes originated from annual moult groups or cohorts that corresponded to ages $3+$ to $7+$ yr. However, the average size of the putative $3+$ cohort appeared greater than expected, probably due to the exclusion of sub-legal individuals from the fishery sample. The neurolipofuscin derived size-at-age data nevertheless highlighted that each size group was a heterogeneous mix of multiple age groups. 


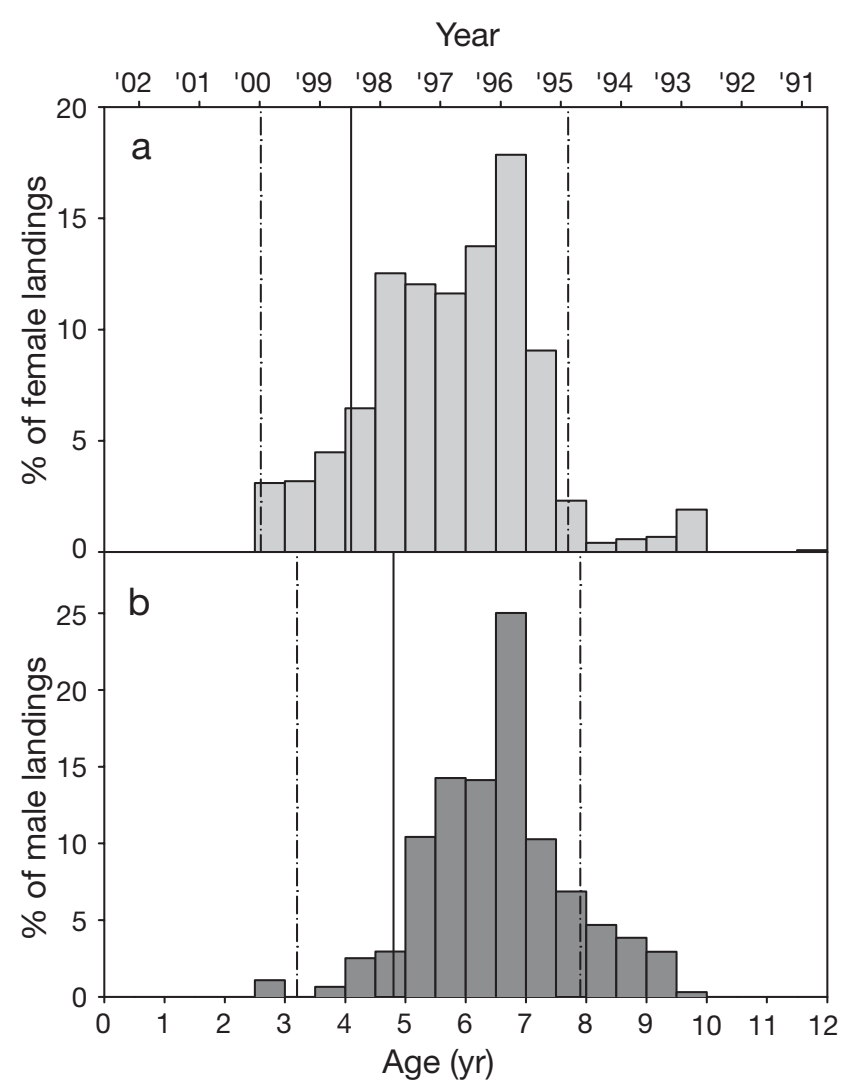

Fig. 6. Cancer pagurus. Neurolipofuscin-estimated age- and year-class compositions for (a) female and (b) male western English Channel inshore landings for 2002; solid and dotteddashed vertical lines: mean age at recruitment to legal size and its $95 \%$ prediction limits, respectively, based on sizeat-age regressions (Fig. 4)

\section{DISCUSSION}

\section{Cohort detection by size and neurolipofuscin concentration}

Size frequency distributions are more useful than NCFDs for resolving the $0+$ and $1+$ cohorts of Cancer pagurus, since neurolipofuscin concentrations are minimal, while their growth rate is relatively high and individual size variation still relatively low. This also appears to be the first report of possible annual peaks in a size frequency distribution for adult C. pagurus. We are not aware of size-stratified sampling having been used on this species previously. Intuitively, one might expect size-selective sampling to obscure natural variations in the abundance of different size classes. However, provided that broad mass or size strata are used that are at least 3 or 4 times wider than the size-classes to be employed in the size frequency histogram (e.g. Sheehy et al. 1998), sampling is effectively random for each class within a stratum. This

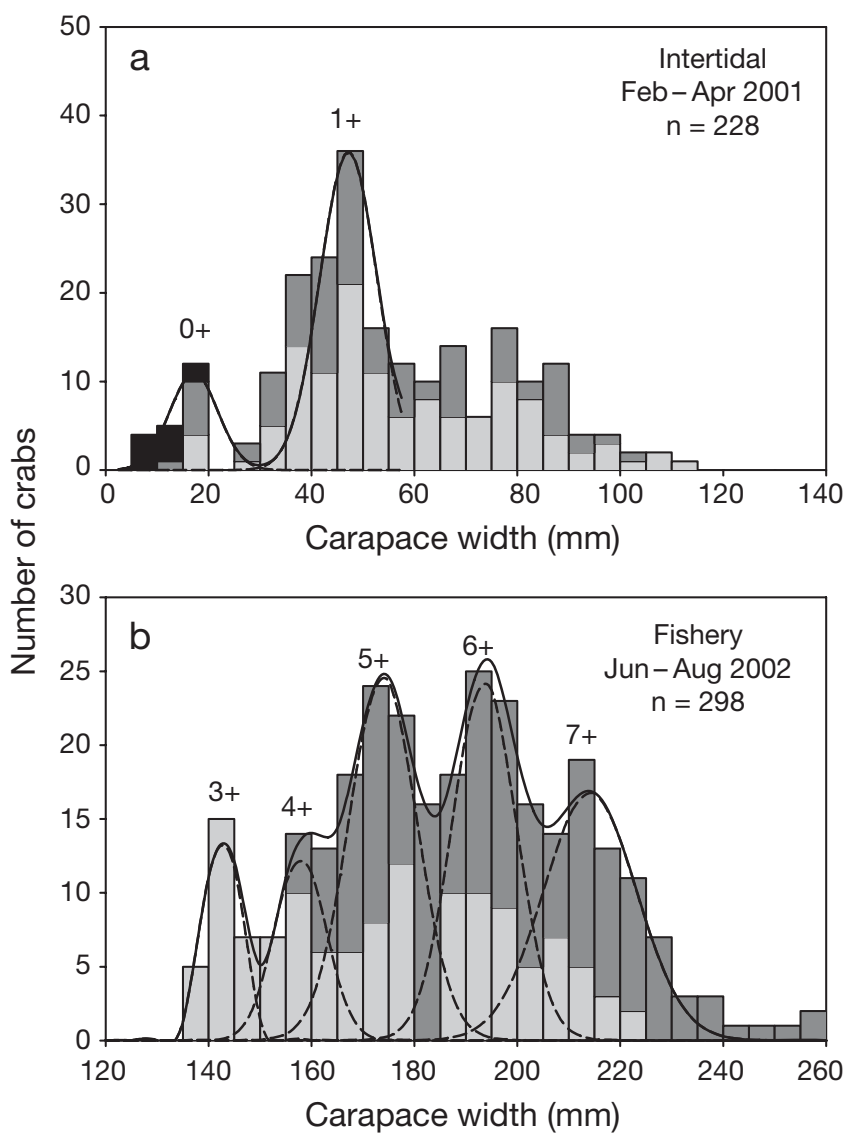

Fig. 7. Cancer pagurus. Modal analysis of size frequency distributions for (a) intertidal and (b) fishery samples; light grey, dark grey and black bars: female, male and undetermined sex, respectively; dashed and solid lines: best-fitting Gaussian components and cumulative Gaussian fit, respectively; $0+$ to 7+: annual cohort designations

technique results in amplification of otherwise poorly resolved, mainly older peaks, while reducing the masking effect of otherwise dominant, mainly younger peaks. Deliberately, in this preliminary examination, we have not split our size frequency data into separate sexes in order to avoid the adverse effects of low sample size in this type of analysis (France et al. 1991) and on the basis that neurolipofuscin analysis indicated that generalized growth was similar for males and females over most of the age range of the peaks detected. Future validation of these results would require time series of stratified size frequency distributions to trace modal progression, using larger sample sizes and separate analyses for each sex.

For legal-sized crabs, the finding that the NCFD produced generally better cohort resolution than that for size, with the former suggesting 3 hidden age classes in the latter $(2+, 8+$ and $9+)$, is consistent with previous results for several other decapods (Sheehy et al. 1998, Bluhm \& Brey 2001, Bluhm et al. 2001, Kodama et al. 2005, Fonseca \& Sheehy 2007). This appears to arise 
from fundamental differences in the nature of development and ageing, in particular the diminution of growth following maturation as opposed to lifelong respiratory catabolism and lipofuscinogenic oxidative damage. Missed cohorts in size frequency distributions are likely to lead to significant biases in parameter estimates (Fonseca \& Sheehy 2007).

\section{Growth}

Addison \& Bennett (1992, p. 86) noted a 'clear need to collect reliable growth data to calculate accurate estimates of fishing mortality...' and the present results help reduce previous uncertainty. Our data, indicating a progressive (exponential) growth phase in early juveniles are consistent with past observations based mainly on laboratory rearing (Edwards 1965, Bennett 1974, ICES 2003). The early lag also corresponds to the first over-wintering period experienced by crabs, and it cannot be adequately described by the standard von Bertalanffy growth model, or the Fabens construct normally applied to anniversary tag-recapture data. A sigmoid type model appears to be the most appropriate form for describing growth of Cancer pagurus over its lifespan. While our growth curves fall within the wide range of options previously applied in stock assessments (Bennett 1974, Addison \& Bennett 1992) they are, nonetheless, not identical to any prior estimates. This may be because neurolipofuscin-based estimates are not subject to a number of potential biases associated with anniversary tag-recapture (Hancock \& Edwards 1967, Bennett 1979, 1995, Francis 1988, Addison \& Bennett 1992). The flattening of the upper portion of the current growth curves, unlike most of those used in recent stock assessments to facilitate application of Length Cohort Analysis (LCA) (Addison \& Bennett 1992), is consistent with Bennett's (1974) tagging data, which shows that crabs of $>190 \mathrm{~mm}$ CW do not appear to moult. Our results confirm Bennett's (1974) speculation that giant males might represent the upper extreme of growth variability rather than being very old. This growth variability has other important implications for stock assessment. As for Homarus gammarus (Sheehy et al. 1999, Sheehy \& Bannister 2002), it is likely to render LCA dysfunctional for estimating mortality because differences in length cannot be related validly to differences in time/age. Protracted recruitment to legal size will tend to stabilize annual landings but may also hide year-class failures and obscure the true spawner recruit relationship (Sheehy 2001), which may explain Addison \& Bennett's (1992) observation that major changes in exploitation patterns can occur over time, with little effect on the size compositions used for assessment. It also heightens the probability of size-selective fishing effect (Jamieson et al. 1998, Sheehy et al. 1999).

\section{Longevity and mortality}

The present study reports the first size-independent estimate of the longevity of Cancer pagurus at around a decade in the western English Channel. This is in good agreement with estimates for the congeneric $C$. magister, which range up to $9 \mathrm{yr}$ (Butler 1961), and supports the status of Cancer as a relative $r$-strategist by comparison with Homarus (Cobb et al. 1997, Sheehy et al. 1999).

Previous estimates of $M$ for Cancer pagurus are speculative and relatively low (males, 0.14; females, 0.06; Bennett 1979), based on the notion that, like lobsters, crabs are large heavily armoured benthic invertebrates, resistant to predation. However, this reasoning ignores other important sources of extrinsic natural mortality such as storm burial/wash-out, temperature extremes, oxygen depletion and pathogens, as well as intrinsic natural mortality due to moult failure and senescence. Based on the new estimates of longevity for $C$. pagurus, $M$ is somewhat higher (0.48) than previously assumed. This is likely to have an effect on yield forecasts and target exploitation rates for the fishery.

In the context of edible crab stock assessment, it has been stated recently that the estimation of mortality parameters through the use of age based models is impossible, because age determination of decapod crustaceans is difficult and time consuming (Woll et al. 2006). However, the present study and several previous ones have demonstrated that, with a modicum of expertise, estimation of mortality using age-structured data is readily possible (Sheehy et al. 1998, Bluhm \& Brey 2001, Bluhm et al. 2001, Sheehy \& Shelton 2001) and, as methods become established, may involve minimal expense (Fonseca \& Sheehy 2007). Nevertheless, the present catch-curve-based estimates of $Z$ suffer from the usual problems associated with use of a steady-state, pseudo-cohort approach, in combination with spatio-temporal variability in crab distribution, gear-selectivity and catchability variation. In the future it will be possible to eliminate at least some of these problems by, for example, tracking the decay of individual year classes in time series of NCFDs (e.g. Kodama et al. 2006). The present $Z$ estimates (females, 0.93 ; males, 1.16) are about twice as high as those of Bennett (1979) (females, 0.5; males, 0.6), but this difference appears to be primarily due to our relatively high $M$ estimates because our $F$ values (females, 0.45 ; males, 0.67) were similar to those of Bennett (1979) 
(females, 0.45; males, 0.46). If the apparent increases in $M$ over the past $30 \mathrm{yr}$ are taken at face value, environmental change and/or selective fishing effect on life history traits would be possible explanations.

\section{Early recruitment variation}

According to our results, western English Channel landings of Cancer pagurus in the early part of the current decade were exclusively derived from settlement during the 1990s and particularly from the mid- to late 1990s. There are strong indications of settlement variation both as vertical clusters in the size-at-age data and in the catch age distributions, in particular the dominant $6+$ age class, corresponding to 1995 settlement. Some independent evidence for the strength of this year class comes from the International Beam Trawl Survey data for the southern North Sea, 1992 to 2000 (which we became aware of after completion of the neurolipofuscin demographic analysis, courtesy of CEFAS, Lowestoft). The 1997 survey produced exceptionally high numbers of small crabs in the 30 to $39.9 \mathrm{~mm}$ CW size class, estimated to be around 2 yr of age. Following several cooler years, 1995 UK coastal waters were relatively warm and it may be that the apparently enhanced settlement in that year represents an environment-recruitment relationship. This would help explain recent increases in crab landings as sea temperatures rise.

\section{Crab migration and thermal correction of age estimates}

Neurolipofuscin accumulation rate is sensitive to temperature (Sheehy 2002b) and this necessitates an analysis of the implications of both inter-annual variations in sea temperature and the westward migration of adult female crabs in the Channel on the current age estimates. Sheehy \& Bannister (2002) presented techniques for correcting age estimates for the effect of spatial and temporal environmental temperature variation on neurolipofuscin accumulation rate and noted that an important effect of thermal correction was to improve the resolution of year class strengths in age compositions. They noted that without such correction, it would have been possible to detect real fluctuations in Homarus gammarus settlement strength, but impossible to place such fluctuations in a more precise historical context. For example, one minor manifestation of the lack of thermal correction of the present Cancer pagurus age estimates is that the distance between the arrowed vertical clusters of size-at-age observations corresponding to $1+$ and 2+ cohorts (mainly 1999 and
1998 year classes, respectively) in Fig. 4 appears less than 1 yr. This is because sea temperature in the year 2000 , i.e. the likely year of onset of neurolipofuscin accumulation for the 1998 year class, was relatively cool by comparison with adjacent years. Although beyond the scope of the present paper, we have obtained such thermal coefficients and corrections solely by regional extension of the methods employed above (Sheehy \& Prior 2005). It will suffice to summarize here that thermally corrected ages for C. pagurus in the western English Channel, and the assessment parameters derived from them, generally differ little from those reported here. Unlike H. gammarus (Sheehy \& Shelton 2001), cohort resolution in C. pagurus NCFDs is good, despite migration and before thermal correction of age estimates, and the crab's shorter lifespan (and thus thermal history) also appears to reduce the need for such correction.

Acknowledgements. This project was funded by the British Government's Department of Environment, Food and Rural Affairs (DEFRA) under Marine Fisheries R\&D contract MF0225 to M.R.J.S. The advice and support of the project officers, R. C. A. Bannister and J. T. Addison (CEFAS, Lowestoft), and J. Lock (DEFRA, London) are gratefully acknowledged. S. R. Lovewell and D. Eaton (CEFAS, Lowestoft) provided size compositions for commercial crab landings in the western English Channel and International Beam Trawl Survey data for the southern North Sea, respectively. M. Smith and C. D'Lacey (University of Leicester) assisted with histology and confocal microscopy, respectively. A. Hutchings (Britannia Shellfish, Beesands) supplied crabs from the western English Channel fishery.

\section{LITERATURE CITED}

Addison J, Bennett D (1992) Assessment of minimum landing sizes of the edible crab, Cancer pagurus, on the east coast of England. Fish Res 13:67-88

Bennett D (1974) Growth of the edible crab (Cancer pagurus L) off southwest England. J Mar Biol Assoc UK 54:803-823

Bennett D (1979) Population assessment of the edible crab (Cancer pagurus L) fishery off southwest England. Rapp PV Réun Cons Int Explor Mer 175:229-235

Bennett D (1995) Factors in the life history of the edible crab (Cancer pagurus L) that influence modelling and management. ICES Mar Sci Symp 199:89-98

Bluhm BA, Brey T (2001) Age determination in the Antarctic shrimp Notocrangon antarcticus (Crustacea: Decapoda), using the autofluorescent pigment lipofuscin. Mar Biol 138:247-257

Bluhm BA, Brey T, Klages M (2001) The autofluorescent age pigment lipofuscin: key to age, growth and productivity of the Antarctic amphipod Waldeckia obesa (Chevreux 1905). J Exp Mar Biol Ecol 258:215-235

Butler TH (1961) Growth and age determination of the Pacific edible crab, Cancer magister Dana. J Fish Res Board Can 18:873-891

Cobb JS, Booth JD, Clancy M (1997) Recruitment strategies in lobsters and crabs: a comparison. Mar Freshw Res 48: 797-806 
Edwards E (1965) Observations on growth of the edible crab (Cancer pagurus). Rapp Cons Int Explor Mer 156:62-70

Edwards E (1979) The edible crab and its fishery in British waters. Fishing News Books, Surrey

Edwards E (1989) Crab fisheries and their management in the British Isles. In: Caddy JF (ed) Marine invertebrate fisheries: their assessment and management. John Wiley \& Sons, New York, p 241-259

Ettershank G (1983) Age structure and cyclical annual size change in the Antarctic krill, Euphausia superba. Polar Biol 2:189-193

FAO (Food and Agriculture Organization) (2006) Fishery statistical collections-FIGIS data collection. Fishery Information, Data and Statistics Unit (FIDI), Luca Garibaldi, United Nations FAO, Rome

Fonseca DB, Sheehy MRJ (2007) Does size matter? A cautionary experiment on overoptimism in length-based bioresource assessment. Can J Fish Aquat Sci 64:996-1008

Fonseca DB, Brancato CL, Prior AE, Shelton PMJ, Sheehy MRJ (2005) Death rates reflect accumulating brain damage in arthropods. Proc R Soc Lond B Biol Sci 272:1941-1947

Fonseca DB, Sheehy MRJ, Shelton PMJ (2003) Unilateral eyestalk ablation reduces neurolipofuscin accumulation rate in the contra-lateral eyestalk of a crustacean, Pacifastacus leniusculus. J Exp Mar Biol Ecol 289:277-286

France R, Holmes J, Lynch A (1991) Use of size-frequency data to estimate the age composition of crayfish populations. Can J Fish Aquat Sci 48:2324-2332

Francis RICC (1988) Are growth parameters estimated from tagging and age-length data comparable? Can J Fish Aquat Sci 45:936-942

Hancock DA, Edwards E (1967) Estimation of annual growth in the edible crab (Cancer pagurus L). J Cons Int Explor Mer 31:246-264

Hoenig JM (1983) Empirical use of longevity data to estimate mortality rates. Fish Bull 81:898-903

ICES (2003) Living resources committee report of the study group on the biology and life history of crabs. International Council for the Exploration of the Sea, Copenhagen, CM 2003/G:11 Ref D

Jamieson GS, Phillips A, Smith BD (1998) Implications of selective harvests on Dungeness crab (Cancer magister) fisheries. In: Jamieson GS, Campbell A (eds) North Pacific symposium on invertebrate stock assessment and management. Can Spec Publ Fish Aquat Sci 125:309-321

Kodama K, Yamakawa T, Shimizu T, Aoki I (2005) Age estimation of the wild population of Japanese mantis shrimp Oratosquilla oratoria (Crustacea: Stomatopoda) in Tokyo Bay, Japan, using lipofuscin as an age marker. Fish Sci 71: 141-150

Kodama K, Shiraishi H, Morita M, Horiguchi T (2006) Verifi-

Editorial responsibility: Howard Browman (Associate Editorin-Chief), Storebø, Norway cation of lipofuscin-based crustacean ageing: seasonality of lipofuscin accumulation in the stomatopod Oratosquilla oratoria in relation to water temperature. Mar Biol 150: $131-140$

Pearson J (1908) Cancer (the edible crab). Mem Liverpool Mar Biol Comm 16:1-263

Robinson M, Tully O (2000) Seasonal variation in community structure and recruitment of benthic decapods in a subtidal cobble habitat. Mar Ecol Prog Ser 206:181-191

Sheehy MRJ (2001) Implications of protracted recruitment for perception of the spawner-recruit relationship. Can J Fish Aquat Sci 58:641-644

Sheehy MRJ (2002a) A flow-cytometric method for neurolipofuscin quantification and comparison with existing histological and biochemical approaches. Arch Gerontol Geriatr 34:233-248

Sheehy MRJ (2002b) Role of environmental temperature in ageing and longevity: insights from neurolipofuscin. Arch Gerontol Geriatr 34:287-310

Sheehy MRJ, Bannister RCA (2002) Year-class detection reveals climatic modulation of settlement strength in the European lobster, Homarus gammarus. Can J Fish Aquat Sci 59:1132-1143

Sheehy MRJ, Prior AE (2005) Analysis of stock age structure and population parameters in edible crab, Cancer pagurus, using lipofuscin age pigments: data for resource management. Marine Fisheries R \& D Final Report MF0225, Department for Environment, Food and Rural Affairs, London

Sheehy MRJ, Shelton PMJ (2001) Use of lipofuscin age pigment for age determination of lobsters. Marine Fisheries R \& D Final Report MF0215, Ministry of Agriculture Fisheries and Food, London

Sheehy MRJ, Caputi N, Chubb C, Belchier M (1998) Use of lipofuscin for resolving cohorts of western rock lobster (Panulirus cygnus). Can J Fish Aquat Sci 55:925-936

Sheehy MRJ, Bannister RCA, Wickins JF, Shelton PMJ (1999) New perspectives on the growth and longevity of the European lobster (Homarus gammarus). Can J Fish Aquat Sci 56:1904-1915

Sokal RR, Rohlf FJ (1981) Biometry, 2nd edn. WH Freeman, San Francisco, CA

Sparre P, Venema SC (1998) Introduction to tropical fish stock assessment. Part 1. Manual. United Nations Food and Agriculture Organization, Fisheries Technical Paper No. 306/1, Rev. 2. United Nations Food and Agriculture Organization, Rome

Woll AK, van der Meeren GI, Fossen I (2006) Spatial variation in abundance and catch composition of Cancer pagurus in Norwegian waters: biological reasoning and implications for assessment. ICES J Mar Sci 63:421-433

Submitted: September 8, 2006; Accepted: July 10, 2007

Proofs received from author(s): December 17, 2007 